\title{
Personality Traits in Juvenile Delinquents: Associations with Peer and Family Relations
}

Jeffrey J. Wilson M.D.

Columbia University Department of Psychiatry

Sharon E. Willams Ph.D.

Stanford University Department of Psychiatry

Evan Garner M.D.

Stanford University

Elaine Duxbury B.A.

Department of the Youth Authority, Sacramento, CA

Hans Steiner Dr. Med. Univ.

Stanford University Department of Psychiatry

Follow this and additional works at: https://jdc.jefferson.edu/jeffjpsychiatry

Part of the Psychiatry Commons

Let us know how access to this document benefits you

\section{Recommended Citation}

Wilson, Jeffrey J. M.D.; Willams, Sharon E. Ph.D.; Garner, Evan M.D.; Duxbury, Elaine B.A.; and Steiner, Hans Dr. Med. Univ. (2001) "Personality Traits in Juvenile Delinquents: Associations with Peer and Family Relations," Jefferson Journal of Psychiatry. Vol. 16 : Iss. 1 , Article 6.

DOI: https://doi.org/10.29046/JJP.016.1.005

Available at: https://jdc.jefferson.edu/jeffjpsychiatry/vol16/iss1/6

This Article is brought to you for free and open access by the Jefferson Digital Commons. The Jefferson Digital Commons is a service of Thomas Jefferson University's Center for Teaching and Learning (CTL). The Commons is a showcase for Jefferson books and journals, peer-reviewed scholarly publications, unique historical collections from the University archives, and teaching tools. The Jefferson Digital Commons allows researchers and interested readers anywhere in the world to learn about and keep up to date with Jefferson scholarship. This article has been accepted for inclusion in Jefferson Journal of Psychiatry by an authorized administrator of the Jefferson Digital Commons. For more information, please contact: JeffersonDigitalCommons@jefferson.edu. 


\title{
Personality Traits in Juvenile Delinquents: Associations with Peer and Family Relations
}

\author{
Jeffrey J. Wilson, M.D., ${ }^{1}$ Sharon E. Williams, Ph.D., ${ }^{2}$ \\ Evan Garner, M.D., ${ }^{3}$ Elaine Duxbury, B.A., ${ }^{4}$ and \\ Dr. Med. Univ. Hans Steiner ${ }^{5}$
}

\begin{abstract}
Objective: To establish family and peer correlates of personality traits shown to be predictive of future criminal recidivism.

Method: 137 incarcerated boys aged 13-18 ( $x=16 \pm 1.2), 35 \%$ black, 21\% Hispanic, 43\% white, and $1 \%$ other completed the Weinberger Adjustment Inventory (WAI) and a psychosocial history obtained by a social worker. Records were summarized using two raters who assigned numerical ratings to dimensions of family and peer relations.

Results: As expected, observer ratings of family and peer relationships were correlated with the personality characteristics of distress, denial and restraint as measured by the WAI.

Conclusion: Family and peer relations are associated with certain personality traits that are predictive of criminal recidivism in delinquents. This study further expands the knowledge base regarding the social and interpersonal correlates of individual traits predicting criminal recidivism.

\section{INTRODUCTION}

Few issues perplex modern society more than delinquency. The cost of delinquent crime is pervasive, including the devastating price the victims pay, the public and appropriate fear for safety in many U.S. cities, the price the society pays to care for these incarcerated youth, and the toll that a crime path extorts from the individual delinquent. Worldwide, increasing attention is being paid to the development of conduct problems and delinquency. As a result of public interest and funding, considerable gains have been made in the scientific understanding of delinquency, particularly related to the classification and epidemiology of conduct problems among youth (1).

Crime among youth is a complex phenomenon. While young people under 25

\footnotetext{
${ }^{1}$ Jeffrey J. Wilson, M.D. Clinical Research Fellow in Adolescent Substance Abuse at Columbia University, Department of Psychiatry, Division on Substance Abuse.

${ }^{2}$ Sharon E. Williams, Ph.D. is Assistant Professor of Psychiatry at Stanford University, Department of Psychiatry, Division of Child and Adolescent Psychiatry.

${ }^{3}$ Evan Garner, M.D. Resident in Psychiatry at Stanford University.

${ }^{4}$ Elaine Duxbury, B.A. is Chief of Research at the Department of the Youth Authority, Sacramento, CA.

${ }^{5}$ Dr. Med. Univ. Hans Steiner is Professor of Psychiatry and Director of Training at Stanford University, Department of Psychiatry, Division of Child and Adolescent Psychiatry.
} 
commit half of nonfatal violent crime, they also face the highest risk of assault (2). The relationship between youth violence and exposure to violence during childhood is strongly suggested by the risk engendered for conduct disorder when a child is abused (3). In fact, witnessing violence has been shown to increase antisocial behavior in high risk, urban boys (4). The perpetrators of these violent crimes are very often victims themselves, and mental health workers are increasingly aware of the psychopathology of criminal behavior and its antecedents.

Aichorn's study of Wayward Youth in 1935 (5) elegantly describes neurotic underpinnings of delinquent behavior for a group of youth. In 1946, Bowlby's landmark study of 44 thieves (6) postulates environmental antecedents to delinquent behavior from the perspective of object relations. Theoretically, family practices are thought to be vital in learning related to behavioral regulation. The development of self-regulation appears to reduce the need for external control and promote broader socialization outside the family. As cited by Weinberger (21), both psychoanalytic (7) and social cognitive theories (8) propose that self-regulatory controls develop primarily within the context of these early family relationships. Some authors question the relative contributions of these parental and peer environmental influences. Recently, Judith Rich Harris (1998) (9) concludes that there is little evidence for any parental nurturing influence on juvenile behavior.

Despite these questions, the literature as well as clinical wisdom suggests a powerful role for both parental and peer influences on delinquent behavior. Attachment difficulties are implicated in the etiology of disruptive behavioral disorders. For example, disorganized attachment status at 12 months has been shown prospectively to predict higher aggressive problems at age 5 (10). Moreover, family factors such as parental rejection, lack of involvement, and low levels of monitoring of the child predict the later development of conduct disorder and delinquency (11). In fact, Patterson, DeBaryshe, and Ramsey (1989) show that family interactions and parent practices account for $30 \%-40 \%$ of the variance in antisocial behavior (12).

Peer influences are also involved in the behavioral expression of psychological traits such as aggressiveness. For example, Elliott et al (1985) have shown that delinquency is predicted by deviant peer relations (13). "Peer pressure" is a common term used by schools and mental health professionals alike. Peer influences may not be completely isolated from family factors, however. For example, consider DiLalla et al (1988): while they find a significant relationship between lax punishment and high aggressiveness, they also relate parent ratings of youth aggressiveness to both high turmoil in the home, and youths' positive opinions of delinquent peers (14).

While this relationship between parental and peer relations is likely to be bidirectional, there is a considerable body of knowledge suggesting that the initial individual development of internal controls is related to parenting. Ainsworth (1989) suggests that secure attachment facilitates the process of successful individuation by providing a secure base from which to explore the world (15). Familial attachments and later familial relationships are important in the development of both extrafamilial relationships and individual coping styles (16). These results provide evi- 
dence that a secure parental base facilitates the development of peer relationships, possibly by fostering the development of internal controls such as self-restraint.

There appears to be a relationship between family environment and individual psychological development. Positive and negative family characteristics correlate with mature and immature defenses, respectively, in adolescent females (17). These data imply that the context in which personality development occurs is intimately involved with the development of internal psychological constructs, i.e., defense mechanisms. More generally, secure parental attachments and peer relationships also appear to facilitate the development of coping resources, with the former being related to greater resourcefulness (18). Among non-clinical populations, it is clear that familial influences continue into adolescence and provide support to the developing adolescent by weakening peer influences on potentially dangerous behaviors such as substance abuse (19).

The developmental theme of adolescence generally involves the increasing influence of peers with decreasing influence of familial relationships. The relationship between these social spheres is complicated and difficult to separate, particularly considering the internalization of early family influences and their manifestation in personality development. Peer and family relations are interrelated in a complex fashion, and both are strongly suggested to be intimately related to the development of conduct, substance abuse and antisocial personality disorders. Improved understanding of delinquency requires investigation of interactions between social relations (family and peer) and personality traits such as self-restraint.

In order to evaluate the parental role in the development of self-regulation, Feldman \& Weinberger (1994) investigated self-restraint as a mediator of parental influence on delinquent behavior in boys (20). In a longitudinal study of 81 boys and their families (from a non-clinical population), initially in $6^{\text {th }}$ and later in $10^{\text {th }}$ grade, they found that parenting practices are associated with delinquency only indirectly through their association with self-restraint. The first measure of self-restraint, in sixth-grade, predicted delinquent behavior more reliably than parenting in $10^{\text {th }}$ grade. Their work further suggests that by the end of childhood, a relatively stable internal construct of self-restraint can be measured, which has predictive value during later development.

The measure used in this study, the Weinberger Adjustment Inventory, has particular utility for the assessment of socioemotional regulation among delinquent youth. This inventory measures two higher order personality traits, distress and restraint. These broad traits can be placed within the five factor model of personality, and encompass 4 (agreeableness, conscientiousness, neuroticism and negative affectivity) of these 5 dimensions (21). Abnormal levels of distress and restraint have been related to various problems, including: delinquent behaviors, posttraumatic stress disorder among delinquents (28), and alcohol use among college students (48). Distress and restraint are related to several dimensions of the Minnesota Multiphasic Personality Inventory (MMPI), but may be a more favorable personality measure for the delinquent population (22). Among delinquent youth, these traits are linked to delinquent behavior cross-sectionally, retrospectively and prospectively $(23,24,25)$. 
These measures of distress and restraint have been suggested to inform psychotherapeutic approaches to delinquents and to delineate four types of delinquency based on high and low scores of restraint and distress $(27,29)$. The profiles described (Reactive, Suppressor, Repressor and Low Reactive) discriminate future criminal recidivism among incarcerated delinquents $(25,50)$.

The affective dimension, distress, is defined as individuals' tendencies to feel dissatisfied with themselves and their subjective perceptions of their abilities to achieve desired outcomes. In this measure, four subtypes are operationally defined: proneness to anxiety, depression, low self-esteem, and low well-being. Examples of these items follow, respectively: "I spend a lot of time thinking about things that might go wrong," "I often feel that nobody really cares about me the way I want them to," "I really don't like myself very much," and "I enjoy most of the things I do during the week." (This last item is rated inversely.)

Self-restraint refers to tendencies across the lifespan to inhibit immediate, self-focused desires in the interest of promoting long-term goals and positive relations with others. Self-restraint is also operationally divided into four subdimensions: suppression of aggression, impulse control, consideration of others, and responsibility. Examples of these items follow, respectively: "When someone starts a fight with me, I fight back," "I stop and think things through before I act," "I think about other people's feelings before I do something they may not like," and "I make sure I stay out of trouble." (The first of those items is rated inversely). Externalizing behavior, as measured by the Child Behavior Checklist, is strongly related to low self-restraint (26).

This study seeks to expand on previous study of the relationship between conduct problems in youth and their social correlates by examining a highly disturbed group of youth in an incarcerated setting. The objective of this study is to establish family and peer correlates of personality traits, which are predictive of future criminal recidivism. It is hypothesized that personality traits that are predictive of criminal recidivism will be associated with aversive family relationships as well as poor peer relations.

\section{METHODS}

\section{Subject Selection}

A sample of 137 adolescent boys from $13-18$ years of age $(\mathrm{x}=16, \mathrm{o}=1.2 ; 43 \%$ White, 35\% Black, 21\% Hispanic, and 1\% other) was selected from incarcerated youth offenders at the California Youth Authority's O.H. Close School in Stockton, CA. More than half of the offenders are incarcerated for violent offenses, and the median number of prior offenses is 4. Subjects completed a narrative of their committing offense, Weinberger Adjustment Inventory scored by a licensed psychologist, and an evaluation by a psychiatric social worker. Records were summarized by 2 independent raters trained by and under the supervision of a board-certified research Child \& Adolescent Psychiatrist and a licensed research psychologist. 


\section{Measures}

The Weinberger Adjustment Inventory (30) is an 84 item self-report questionnaire measuring two main dimensions, distress (29 items tapping four dimensions: anxiety, depression, low well being, and self-esteem; alpha $=.81)$ and restraint (30 items in 4 dimensions: impulse control, suppression of aggression, responsibility, and consideration of others; alpha $=.86$ ), as well as measures of defensiveness and denial. This scale has been shown to have reliable psychometric properties and to display convergent, discriminant and predictive validity $(20,29)$.

Family and peer relations were rated by 2 raters blind to the WAI results. One rater evaluated family relations, while a second evaluated peer relations. Family and peer relations were scored from criminological records of the ward's committing offense and from the evaluation by the psychiatric social worker. Family relations were rated for the presence of parental figures (no, maybe, yes), strength of attachment (1-10), objective health of the family (1-10), ward's perception of family's health (1-10), and the clear presence of abuse (yes, no). Peer relations were rated in four independent categories: Normal, gang, delinquent, and drug-related (no, maybe, yes).

\section{Statistics}

A series of Spearman correlation coefficients were performed in order to evaluate the associations between: 1. Family relations and personality characteristics, and 2. Peer relations and personality characteristics.

\section{RESULTS}

Superordinate Personality Dimensions and Social Relations

1. Family relations and personality. $38.0 \%$ of our subjects reported an absent or inconsistently present mother figure, and $79.6 \%$ reported an absent or inconsistently present father figure. $78.8 \%$ of the subjects reported some kind of abuse. The most robust family relations variable is child abuse, which positively correlates with distress $(+.227, \mathrm{p}=.008)$, and denial $(+.224, \mathrm{p}=$ .008). (In an effort to keep the directions of the family variables uniform, we will hereafter describe abuse in the opposite direction, i.e., nonabusive parenting.) Presence or absence of parental figures, objective or subjective measures of family health, or self-reports of attachment to parental figures are not significantly correlated with measures of distress. Contrary to our hypotheses, family relations measures are not associated with measures of restraint, except perhaps for a trend indicating a relationship between the subscale of responsibility and nonabusive parenting.

2. Peer relations and personality. "Normal" peer relations are significantly associated with the measure of restraint $(+.189, \mathrm{p}=.027)$. Gang-related, delin- 
TABLE 1.

Relationships Between Family, Peer and Personality Trait Subscales Among Incarcerated Delinquents

\begin{tabular}{|c|c|c|c|c|c|c|c|c|}
\hline \multirow{3}{*}{$\begin{array}{c}\begin{array}{c}\text { Social } \\
\text { Relations }\end{array} \\
\text { Family }\end{array}$} & \multicolumn{8}{|c|}{ Personality Traits } \\
\hline & \multicolumn{4}{|c|}{ Distress } & \multicolumn{4}{|c|}{ Restraint } \\
\hline & ANX & DEP & SEST & LWB & SAGR & IMPC & CONS & RESP \\
\hline Mom+ & -.027 & -.047 & -.050 & .019 & .059 & .011 & .062 & .116 \\
\hline Pop+ & .099 & .027 & .040 & -.001 & -.074 & -.052 & .023 & -.003 \\
\hline Health Fam & $.187 * *$ & -.070 & $-.154^{*}$ & $-.177 * *$ & .092 & -.065 & .073 & .120 \\
\hline \multicolumn{9}{|l|}{ Nonabusive } \\
\hline Parenting & -.076 & $-.227 * * *$ & $-.188 * *$ & $-.215 * * *$ & .089 & .056 & -.026 & $.159 *$ \\
\hline Attach. & $.176^{* *}$ & -.067 & -.117 & -.131 & .134 & -.019 & .121 & .110 \\
\hline Subj Fam & .092 & -.088 & -.139 & $-.187 * *$ & .092 & -.018 & .066 & .136 \\
\hline Peer & ANX & DEP & SEST & LWB & SAGR & IMPC & CONS & RESP \\
\hline Norm & -.083 & -.092 & -.051 & 0.090 & .107 & $.207 * *$ & .160 & $.154^{*}$ \\
\hline Gang & -.132 & -.044 & -.043 & -.002 & -.129 & .053 & $-.164 * *$ & -.062 \\
\hline Delinq & .068 & .006 & -.073 & .115 & -.021 & .042 & $-.182 * *$ & -.046 \\
\hline Drugs & -.001 & .077 & -.020 & $.220 * * *$ & -.039 & -.040 & -.085 & -.032 \\
\hline
\end{tabular}

$* \mathrm{p} \leq 0.10, * * \mathrm{p} \leq 0.05, * * * \mathrm{p} \leq 0.01$

Distress Subscales

ANX $=$ Anxiety, DEP $=$ Depression, SEST $=$ Low Self-Esteem, and LWB $=$ Low Well Being; Restraint Subscales

SAGR $=$ Suppression of Aggression, IMPC $=$ Impulse Control, CONS $=$ Consideration of Others, and RESP = Responsibility.

quent or drug-related peer relations are not significantly correlated with personality measures, nor are any family relations variables.

In summary, distress among incarcerated delinquents is associated with family relationships, while restraint is associated with peer relationships.

\section{Personality Dimension Subscales and Social Relations}

1. Family relations and personality. Correlations between family variables and distress and restraint subscales of the WAI are summarized in Table 1. Nonabusive parenting is negatively associated with depression, low selfesteem, and low well being (LWB). LWB and anxiety subscales are also associated with objective family health, although in opposite directions: i.e., anxiety (ANX) positively and LWB negatively. In a similar fashion, ANX also associates positively with attachment ratings, while LWB negatively associates with subjective ratings of family health.

2. Peer relations and personality. See Table 1. More normal peer relationships relate to the subscale of impulse control $(\mathrm{r}=.21, \mathrm{p}=.02)$. Consideration of others negatively correlates with gang- and delinquent-oriented peer rela- 
TABLE 2.

Spearman Correlations between Family and Peer Relations among Incarcerated Delinquents

\begin{tabular}{llccr}
\hline & \multicolumn{4}{c}{ Peer Relations } \\
\cline { 2 - 5 } \multicolumn{1}{c}{ Family Relations } & Normal & Gang & Delinquent & Drugs \\
\hline Health Fam & $.200^{*}$ & -.065 & -.143 & -.182 \\
Non-Abusive Parenting & $.241^{* *}$ & .023 & -.143 & -.161 \\
Attachment & $.191^{*}$ & $-.201^{*}$ & .131 & .008 \\
Subj Family & .142 & -.147 & .109 & -.031 \\
\hline
\end{tabular}

tionships $(\mathrm{r}=-.16, \mathrm{p}=.05 ; \mathrm{r}=-.18, \mathrm{p}=.03$; resp). The only distress subscale which relates to peer relations is LWB. LWB is positively correlated with drug-abusing peers $(\mathrm{r}=.22, \mathrm{p}=.01)$.

In summary, distress subscales are associated with family relationships, while restraint subscales are associated more with peer relationships; the only exception being an association between LWB and drug-abusing peers.

Family and Peer Relations

The independent ratings of peer and family relationship characteristics also showed some congruence. Correlations between observer ratings of family relations and peer relations are summarized in Table 2. Normal peer relations positively associate with ratings of attachment strength, family health and nonabusive parenting $(.19, .20$, and .24 , resp). Gang relations negatively correlate with attachment $(-.20)$, and drug-related peer relations negatively correlate with observer ratings of family health (-.18). A trend toward a significant relationship between drug-related relations and child abuse is also reported: $\mathrm{r}=.16, \mathrm{p}=.059$.

\section{DISCUSSION}

Inconsistent with previously reported data in non-clinical populations as well as our hypothesis, restraint is not significantly associated with family relationships among this often-neglected delinquent population (31). There usually is a bidirectional relationship between an individual and his/her social relations which begins in the home (i.e., youth can affect parents as parents can affect youth, Patterson, 1995) (35). Prospective study of youth subjected to child abuse has found that there is an increased risk of disruptive behavioral problems including delinquency (36). It may be that in this highly disturbed population the intrapsychic remnant of family environment is found in more emotional personality traits such as distress (see below). The lack of a relationship between restraint and personality in our study may very likely represent the lack of parenting in this domain, i.e., the development of self-restraint through effective, authoritarian parenting. 
Restraint and its subscales primarily relate to peer relationships, apparently having more of an impact on more recent socialization. Restraint is positively associated with ratings of normal peer relations. In particular, the subscale of restraint, impulse control, was strongly correlated with "normal" peer relations, supporting previous reports of a relationship between impulsivity and peer rejection (32). As might be expected, gang and delinquent peer relations are found to be negatively associated to the WAI subscale of restraint, "consideration of others." Good socialization, as reflected in "normal peer relations," is associated with higher levels of desirable personality characteristics in delinquents. A diminished ability to consider the needs of others may, similarly, reflect poor socialization. This is consistent with previous reports that relate individual psychological characteristics (such as poor impulse control) to peer relation problems among youth with disruptive behavior disorders $(32,33,34)$.

The pattern of the relationships between social relations and personality is interesting. While restraint primarily relates to peer characteristics, distress and its subscales primarily relate to family characteristics. These data suggest that the family environment leaves an impact on these delinquent youth emotionally. Distress, a personality trait also previously shown to be related to criminal historical factors (24), was most strongly associated with a history of abuse, the most robust family variable. Child abuse has been associated with multiple psychological sequellae, including emotional distress (37). Denial was negatively associated with child abuse. A possible explanation for this may be that denial requires at least a modicum of positive family characteristics to be present. Severe abuse may lead to conditions where denial is no longer adaptive. In fact, study of abused children has indicated that denial of abuse is rather uncommon (38). As has been previously suggested by Araujo and Steiner, denial may be an effective defense only up to a certain level of environmental stress (39).

No other significant associations were noted between the WAI measure of distress and family or peer relations, including presence or absence of maternal or paternal figures. This is an interesting finding (or rather, the lack thereof). In the general population, the absence of a parental figure, whether by abandonment, divorce, or death is a potentially devastating insult. Even in milder cases of divorce, some distress is measurable (40). One might also expect that youth involved with drug-abusing, delinquent, or gang-related peers might also experience higher levels of distress. The lack of distress, coupled with the lack of denial and the difficult family environments of this group of youth, suggests an alternative pattern of coping for these delinquent youth.

While over time this distress is likely to be attenuated, it is reasonable to expect that even this rudimentary measure of family functioning (i.e., presence or absence of maternal or paternal figure) would be associated with some measurable emotional distress. Yet with these youth, it is not associated with any significant distress or subscale thereof. One hypothesis is that the toxic parental figures (e.g., severely abusive or neglectful parents) are not missed, either because of their toxicity or because of their neglectful parenting. A second hypothesis is that there is something 
(or something missing) within the youth which prevents emotional attachment (e.g., a developing psychopath).

In our study, objective ratings of attachment are positively associated with anxiety, and negatively associated with gang relationships (see tables 2, and 3, resp). This may indicate that anxiety serves a different function for these youth, and may be a sign of insecure attachment, as reported by Bowlby (1994) (6). Without a modicum of positive family influence, the expected emotional reaction of anxiety may not develop, and only the most disturbed peer relations may be possible. Considering this deficit, gang-related peer relations may indicate a misguided attempt by the youth on some level to compensate for a relative lack of supportive relationships.

Regarding the overall lack of any significant associations between distress and family or peer relations, it is likely that the severity of the abusive and neglectful home situations, coupled with the attendant traumata of the criminal lifestyle, create a ceiling effect that masks variables which might be otherwise expected to be significant in a non-incarcerated population (see introduction). Our exploratory design is limited by our measures of family functioning, based as they are on observer ratings of criminal narratives, which may not be sensitive enough to discriminate between these presumably intensely affected variables. More sensitive family measures might be used in the future to assess the relationship between family relations and personality traits in this highly traumatized population.

Distress subscales are associated with various family relations variables and one peer relations variable. ANX is noted to have a positive, significant association with both objective ratings of family health (Health Fam) and attachment (Attach). Anxiety is usually considered to be an aversive trait, and one would not expect that anxiety would be positively associated with better family functioning. On the other hand, most of these families are not average, and many of these families are abusive or otherwise dysfunctional. In this case, elevated anxiety would be a normal reaction to an abnormal situation, and the relative lack of anxiety is likely to be an indication of anxious insecure attachment.

An additional consideration is that better family functioning might in some fashion be the psychosocial basis for an alternative to criminal behavior; i.e., the family might provide the youth with another perspective on his or her delinquent behavior, a perspective that creates internal conflict and subsequent anxiety. This internal conflict may be first steps on a pathway out of delinquency. These considerations are not necessarily mutually exclusive, and may actually be interrelated. Clearly, assumptions about causality are beyond the power of this study, but noting this initially counterintuitive, positive association yields interesting hypotheses for future work.

As might be expected, low well being (LWB) negatively associates with objective ratings of family health and subjective family health, as well as nonabusive parenting. A particularly interesting association is between LWB and drug-related peer relations. One prior study of non-clinical populations has suggested a pathway from emotional distress to adolescent drug use via the choice of substance-using peers 
(41). Further study might address the question of the relationship between LWB and drug-related peer relations. Many factors may contribute to this relationship including the effects of drug abuse on the individual, self-medication of unpleasant emotional states, and/or unsatisfying peer relations.

Neither restraint nor any of its subscales are found to be significantly associated with substance-using peer relations in our study. Restraint has been previously reported in non-clinical populations to be predictive of substance abuse (42), as has behavioral self-regulation (BSR) (43). BSR has been proposed as a potential factor in the choice of delinquent and substance-abusing peers, and as a prodromal factor for substance abuse among populations at high risk for substance abuse. In our study, generally low restraint (the mean restraint level in our study is 98 , which is the $20^{\text {th }}$ percentile for norms based on non-clinical populations) (30) may have created a basement effect, which masks the influence of restraint on the choice of substance abusing peers.

While, again, correlation does not infer causality, this association yields some interesting hypotheses relating personal well being (or the lack thereof), and drug-related peer relations. It may be that in some fashion, a sense of LWB might contribute to the choice of substance-using peers, and potentially substance abuse. Peer pressures are clearly the greatest proximal correlate of adolescent substance use (44). In addition, substance use (and particularly misuse) may contribute to a personal sense of $\mathrm{LWB}$, which might maintain a vicious cycle of LWB leading to substance use, leading to a worsened personal LWB, and so on. These hypotheses might be explored with further study of this relationship between this particular type of distress and peer choices, as well as substance use.

The weak correlations between family environment and our personality measures are worthy of further consideration. The relations are overwhelmingly negative, with the most robust variable being nonabusive parenting, i.e., the absence of abuse. Considering that the most helpful family measure is the lack of abuse, and that there was no positive effect on either restraint or distress if either parent was present, speaks very little for resiliency factors in this environment. In fact, it points to the subjects' lack of social support. Moreover, attachment in a more healthy family increases anxiety in our highly disturbed population. Only 2 significant correlations (out of 24 total) appeared to be helpful to the emotional state of the delinquents in our study, and these were among the weakest. While not initially hypothesized, this relative lack of significant relationships between family and these personality traits is reasonable considering the extent to which these youth have been neglected and/or abused.

The literature supports the premise that the familial environment is to some extent internalized, in multiple non-clinical studies and in at least one severely delinquent sample. Ruchkin et al (1998) report substantial relationships between parenting practices and personality dimensions among their sample of incarcerated delinquents in Northern Russia (45). While Ruchkin et al found a relationship, the generalizability to our sample is questionable, particularly considering that they exclude families with less than 2 parents. The majority of our subjects in our sample 
had one parent figure, and this person was often abusive. For there to be a stronger relationship, parents have to at least be present, and maybe even helpful. The diminished relationship between family variables and personality traits may actually indicate the lack of functional parenting.

There is some relationship between family and peer relations. In our study, peer relations are correlated with family relations, and healthy family variables are more associated with normal peer relations. Normal peer relationships are positively associated with family health, attachment and nonabusive parenting. In addition, gang-types of peer relations are associated negatively with attachment. Ineffective parental monitoring is highly associated with youth involvement with deviant peers (46). Difficulties with attachment or otherwise attenuated parental relationships (whether by abuse or neglect) are likely to play a role in the choice of deviant peers. While our measure of attachment is not sophisticated enough to determine types of attachment organizations, a dismissing attachment organization has previously been associated with conduct and substance abuse disorders in hospitalized adolescents (47). While we need to be careful not to infer beyond the association, our finding of the significant relationships between peer relations and attachment is consistent with a model of social development where early family experience is intimately involved in the development of extra-familial relationships. The early risk factor of poor family relationships appears to cascade down the developmental pathway, compounding risks along the way.

Although preliminary, and in need of verification with longitudinal study, this study is consistent with a model of personality development where early family experiences are internalized and the consequent personality structures regulate the development of different types of extra-familial relationships, i.e., normal, gang-, delinquent- or drug-related. This research expands the cumulative knowledge regarding the social and interpersonal correlates of individual traits predicting criminal recidivism, and provides leads for further study of the development of peer relationships in criminal delinquency.

\section{ACKNOWLEDGMENTS}

This research is supported by The California Wellness Foundation's grant to Dr. Steiner. We would also like to thank Karen Thomas and Marcia Scipio for providing ratings of ward narratives.

\section{REFERENCES}

1. Steiner H. Practice parameters for the assessment and treatment of children and adolescents with conduct disorder. J Amer Acad Child Adolesc Psychiatry 1997; 36: 1S-18S.

2. Steiner H, Cauffman E. Juvenile justice, delinquency, and psychiatry. Child \& Adolescent Psychiatry Clinics of North America 1998; 7: 653-672. 
3. Finkelhor D, Berliner L. Research on the treatment of sexually abused children: a review and recommendations. J Am Acad Child Adolesc Psychiatry 1995; 34: 1408-1423.

4. Miller LS, Wasserman GA, Neugebauer R, et al. Witnessed community violence and antisocial behavior in high-risk, urban boys. J Clin Child Psychol 1998; 28: 2-11.

5. Aichorn A. Wayward Youth. New York: Viking Press, 1935.

6. Bowlby J. Fourty-four juvenile thieves: their characters and home-life. Int J Psychoanal 1944; 25: 19-53.

7. Tyson P, Tyson RL. Psychoanalytic Theories of Development: An Integration. New Haven, CT: Yale University Press, 1990.

8. Bandura, A. The Social Foundations of Thought and Action. Englewood Cliffs, NJ: Prentice Hall, 1986.

9. Harris JR. The Nurture Assumption: Why Children Turn Out the Way that They Do. New York: Free Press, 1998.

10. Shaw DS, Owens EB, Vondra JI, et al. Early risk factors and pathways in the development of early disruptive behavior problems. Dev Psychopathol 1996; 8: 679-699.

11. Loeber R, Stouthamer-Loeber M. Family factors as correlates and predictors of juvenile conduct problems and delinquency, in Crime and Justice: An Annual Review of Research, Vol. 7. Edited by Tonry M, Morris N. Chicago: University of Chicago Press, 1986: 29-149.

12. Patterson GR, Reid JB, Dishion TJ. A developmental perspective on antisocial behavior. Am Psychol 1989; 44: 329-335.

13. Elliott DS, Huizinga D, Ageton SS. Explaining Delinquency and Drug Use. Newbury Park, CA: Sage, 1985.

14. DiLalla LF, Mitchell CM, Arthur MW, et al. Aggression and delinquency: family and environmental factors. J Youth Adolesc 1988; 17: 233-246.

15. Ainsworth MDS. Attachments beyond infancy. Am Psychol 1989; 44: 709-716.

16. Parke RD, Ladd GW. Family-Peer Relationships: Modes of Linkages. Hillsdale, NJ: Erlbaum, 1992.

17. Thienneman M, Shaw RJ, Steiner H. Defense style and family environment. Child Psychiatry Hum Dev 1998; 28: 189-198.

18. Brack G, Matheny KB, Gay MF. Relationships between attachment and coping resources among late adolescents. J College Student Dev 1993; 34: 212-215.

19. Frauenglass S, Roth DK. Family support decreases influence of deviant peers on Hispanic adolescents' substance use. J Clin Child Psychol 1997; 26: 15-23.

20. Feldman SS, Weinberger DA. Self-restraint as a mediator of family influences on boys' delinquent behavior: a longitudinal study. Child Dev 1994; 65: 195-211.

21. Weinberger DA, Schwartz GE. Distress \& restraint as superordinate dimensions of self-reported adjustment: a typological perspective. Journal Pers 1990; 58: 381-417.

22. Huckaby WJ, Kohler M, Garner EH, et al. A comparison between the Weinberger Adjustment Inventory and the Minnesota Multiphasic Personality Inventory with incarcerated delinquent males. Child Psychiatry Hum Dev 1998; 28: 273-285.

23. Tinklenberg JA, Steiner H, Huckaby WJ, et al. Criminal recidivism predicted from narratives of violent juvenile delinquents. Child Psychiatry Hum Dev 1996; 27: 69-79.

24. Steiner H, Williams SE, Benton-Hardy L. Violent crime paths in incarcerated juveniles: psychological, environmental, and biological factors, in Plenum Publishing Co., NY, 1997.

25. Steiner H, Cauffman E, Duxbury E. Personality traits in juvenile delinquents: relation to criminal behavior and recidivism. J Am Acad Child Adolesc Psychiatry 1999; 38: 256-262.

26. Achenbach TM, Edelbrock C. Manual for the Child Behavior Checklist and Revised Child Behavior Profile. Burlington: University of Vermont, 1983. 
27. Steiner H. Individual psychotherapeutic approaches to violent youth. Lecture at Institute II of the 43rd annual meeting of the American Academy of Child and Adolescent Psychiatry, October 1996.

28. Steiner H, Garcia IG, Matthews Z. Posttraumatic stress disorder in incarcerated juvenile delinquents. J Am Acad Child Adolesc Psychiatry 1997; 36: 357-365.

29. Steiner H, Feldman SS. Two approaches to the measurement of adaptive style: comparison of normal, psychosomatically ill, and delinquent adolescents. J Am Acad Child Adolesc Psychiatry 1995; 34: 180-190.

30. Weinberger DA. Distress and self-restraint as measures of adjustment across the lifespan: confirmatory factor analysis in clinical and non-clinical samples. Psychol Assess 1997; 9: 132-135.

31. Feldman S, Wentzel K. Relations between family interaction patterns, classroom selfrestraint and academic achievement in pre-adolescent boys. J Educ Psychol 1990; 82: 813-819.

32. Hinshaw SP, Zupan B, Simmel C, et al. Peer status in boys with and without attention deficit hyperactivity disorder: predictions from overt and covert antisocial behavior, social isolation, and authoritative parenting beliefs. Child Dev 1997; 68: 880-896.

33. Guevevremont DC, Dumas MC. Peer relationship problems and disruptive behavior disorders. J Emotional Behavioral Disorders 1994; 2: 164-172.

34. Landau S, Milich R, Diener MB. Peer relations of children with attention deficit hyperactivity disorder. Reading and Writing Quarterly: Overcoming Learning Disabilities 1988; 14: 83-105.

35. Patterson GR. Performance Models for Parenting: A Social Interventional Perspective. New York: Wiley and Sons, 1997.

36. Robins LN, Rutter M: Straight and Devious Pathways from Childhood to Adulthood. Cambridge: Cambridge University Press, 1990.

37. Briere JN, Elliott DM. Immediate and long term impacts of child sexual abuse. Future of Children 1994; 4: 54-69.

38. Bradley AR, Wood JM: How do children tell? The disclosure process in child sexual abuse. Child Abuse Neglect 1996; 20: 881-891.

39. Araujo K, Steiner H. Adolescent defense style and life stressors. Child Psychiatry Hum Dev 1999; 30(1): 19-28.

40. Rodgers B: Social and psychosocial wellbeing of children from divorced families: Australian research findings. Aust Psychol 1996; 31: 174-182.

41. Swaim RC, Oetting ER, Edwards RW, et al. Links from emotional distress to adolescent drug use: a path model. J Consult Clin Psychol 1989; 57: 227-231.

42. Farrell AD, Danish SJ. Peer drug associations and emotional restraint: causes or consequences of adolescents' drug use? J Consult Clin Psychol 1993; 61: 327-334.

43. Dawes MA, Tarter RE, Kirisci L. Behavioral self-regulation: correlates and 2 year follow-ups for boys at risk for substance abuse. Drug Alcohol Depend 1997; 45: 165-176.

44. Dishion TJ, Loeber R. Adolescent marijuana and alcohol abuse: the role of parents and peers revisited. Am J Drug Alcohol Abuse 1985; 11: 11-25.

45. Ruchkin VV, Eisemann M, Hagglof B, et al. Interrelations between temperament, character and parental rearing in male delinquent adolescents in northern Russia. Compr Psychiatry 1998; 39: 225-230.

46. Dishion TJ, Capaldi D, Spracklen KM, et al. Peer ecology of male adolescent drug use. Dev Psychopathol 1995; 7: 803-824. 
47. Rosenstein DS, Horowitz HA. Adolescent attachment and psychopathology. J Consult Clin Psychol 1996; 64: 244-253.

48. Weinberger DA, Bartholemew K. Social-emotional adjustment and patterns of alcohol use among young adults. J Pers 1996; 64: 495-527.

49. McCrae RR, Costa PT Jr. Validation of the five-factor model of personality across instruments and observers. J Pers Soc Psychol 1987; 52: 81-90.

50. Steiner H, Wilson JJ. Conduct disorder, in Disruptive Behavior Disorders in Children and Adolescents. Washington, DC: American Psychiatric Press, 1999: 47-98. 